\title{
IFC File Analyzer Software
}

\section{Robert Lipman}

National Institute of Standards and Technology, Gaithersburg, MD 20899, USA

robert.lipman@nist.gov

Software DOI: https://doi.org/10.18434/M3F30P

Software Version: 2.52

Key words: buildings; conformance; IFC; interoperability.

Accepted: March 1, 2017

Published: March 30, 2017

https://doi.org/10.6028/jres.122.015

\section{Summary}

The IFC File Analyzer software generates a spreadsheet or a set of CSV (comma-separated value) files from an IFC file. IFC (Industry Foundation Classes) is the data exchange standard used to facilitate interoperability in the building and construction industry. IFC is developed by buildingSMART [1] and is an ISO standard-ISO 16739 [2].

Typical IFC viewers show a visualization of the building represented by the IFC file. The user can drill down to the individual attributes for a single building object. However, there is no way to view all of the entities and their attributes at once. The IFC File Analyzer provides this capability by creating a spreadsheet or CSV files from the IFC file.

In the spreadsheet, a worksheet is created for each type of IFC entity in the file. Every row in the worksheet contains the attributes for an instance of an IFC entity. Multiple IFC files can be analyzed at once to compare entity usage. There are options to select which types of IFC entities are processed and to report some of the IFC entity Inverse relationships.

\section{Software Specifications}

\begin{tabular}{ll}
\hline NIST Operating Unit(s) & $\begin{array}{l}\text { Engineering Laboratory, Systems Integration Division, Systems } \\
\text { Engineering Group }\end{array}$ \\
\hline Category & Analysis \\
\hline Targeted Users & $\begin{array}{l}\text { Software developers and end-users of IFC files in BIM (Building } \\
\text { Information Modeling) software }\end{array}$ \\
\hline Operating System(s) & Windows \\
\hline Programming Language & Tcl \\
\hline Inputs/Outputs & Inputs: ISO 16739 IFC file. Outputs: Microsoft Excel spreadsheet, \\
\hline Documentation & CSV files \\
\hline Accessibility & https://www.nist.gov/services-resources/software/ifc-file-analyzer \\
\hline Disclaimer & N/A \\
\hline
\end{tabular}




\section{Methods}

This software provides executable files with a graphical user interface and a command-line program. The software uses the IFCsvr toolkit [3] to read IFC files and STEPtools to define IFC schemas [4]. The software has been tested with thousands of IFC files, available from past IFC conformance checking projects, to ensure that all errors in the files are properly handled and that all features of the software work correctly.

\section{References}

[1] Industry Foundation Classes. Available at http://www.buildingsmart-tech.org/. Accessed March 2, 2017.

[2] International Organization for Standardization (2013) ISO 16739:2013 - Industry Foundation Classes (IFC) for data sharing in the construction and facility management industries (International Organization for Standardization, Geneva, Switzerland). Available at https://www.iso.org/standard/51622.html. Accessed March 2, 2017.

[3] Adachi Y (2013) IFCsvr ActiveX Component. Available at https://groups.yahoo.com/neo/groups/ifcsvr-users/info. Accessed March 2, 2017.

[4] Hardwick M (2017) STEPtools. Available at http://www.steptools.com/. Accessed March 2, 2017.

About the author: Robert Lipman is a research engineer at NIST. He develops software and product data to support the exchange of information and development of standards for the smart manufacturing digital thread. The National Institute of Standards and Technology is an agency of the U.S. Department of Commerce. 